\title{
PARA A DEFESA DE UMA ÉTICA AMBIENTAL ANTROPOCENTRADA ${ }^{1}$
}

\author{
TOWARDS AN \\ ANTHROPOCENTRED ENVIRONMENTAL ETHICS
}

MAGDA COSTA CARVALHO ${ }^{2}$

(Universidade dos Açores, Portugal)

\begin{abstract}
RESUMO
Os debates produzidos pelas éticas ambientais contemporâneas tendem a recusar, na sua maioria, qualquer abordagem de fundo antropocêntrico, identificando esta postura com uma desvalorização da natureza em detrimento dos interesses humanos. Para além disso, é comum entenderem-se os interesses da espécie humana como uma instrumentalização abusiva do ambiente, sobretudo com a finalidade de produzir bem-estar social e económico. A presente reflexão pretende contestar estas posições, promovendo uma distinção entre a legítima percepção e valorização da natureza a partir do ponto de vista humano e uma ilegítima atitude de desvalorização e instrumentalização do meio ambiente. Procuraremos defender uma atitude que tem sido caracterizada entre os especialistas como um antropocentrismo fraco ou moderado, cujo alcance e potencialidades éticas não nos parecem ter recebido ainda a devida atenção.
\end{abstract}

Palavras-chave: Antropocentrismo. Valor. Natureza. Ética Ambiental.

\begin{abstract}
Discussions generated by today's environmental ethics tend to decline, in the greater part, any approach with an anthropocentric basis, identifying this position with a devaluation of Nature at the expense of human concerns. Furthermore, it is common to regard human concerns as an abusive exploitation of the Environment, especially in order to produce social and economic well-being. The current paper aims at contesting these standpoints by promoting a distinction between the legitimate perception and valuation of Nature from the human point of view and the illegitimate attitude of devaluation and exploitation of the Environment. We shall seek to defend an attitude that has been called, among experts, a weak or moderate anthropocentrism, whose reach and ethical potential have not yet been properly considered.

Keywords: Anthropocentrism. Value. Nature. Environmental Ethics.
\end{abstract}

A Ética Ambiental surgiu como resposta à representação da natureza enquanto reservatório inesgotável de recursos com um ilimitado poder gerador e regenerativo, perspectiva que, a partir de meados do século $\mathrm{XX}$, foi maioritariamente identificada como a responsável pela crise ambiental contemporânea.

Neste processo de identificação de responsáveis, e na consequente procura de soluções para problemas cuja gravidade ultrapassava já o limite do que o nosso modo de vida na Terra comporta, surgiu, então, uma espécie de conceito guarda-chuva. O antropocentrismo foi albergando diversas interpretações e comportando uma indesejável ambiguidade de sentidos. 
A sua formalização coincidiu com o nascimento da Ética Ambiental e foi entendido como o inimigo que esta nova ética aplicada viria combater.

Ainda que a simplicidade da generalização acima apresentada não esgote a complexidade e a riqueza do debate ético ambiental das últimas décadas, na verdade ainda hoje as principais tendências desta área situam-se num horizonte teórico polarizado entre posições antropocêntricas e posições não antropocêntricas.

A presente reflexão tem por objetivo chamar a atenção para quatro equívocos presentes neste modo de entender a Ética Ambiental, apresentando algumas críticas aos autodesignados "não antropocentrismos".

Centrar-nos-emos em quatro conceitos-chave - antropocentrismo, valor, natureza e ética ambiental -, referindo o que consideramos serem quatro equívocos ou interpretações enviesadas de cada um deles e procurando apresentar perspectivas através das quais poderiam os mesmos ser mais coerente e eficazmente entendidos: o antropocentrismo como opção epistemológica; o valor como propriedade das coisas; o conceito des-humanizado de natureza; a ética ambiental como filosofia aplicada.

\section{O antropocentrismo como opção epistemológica}

Há necessidade de uma nova ética, uma ética ambiental?

Com esta interrogação como título de uma comunicação ao $15^{\circ}$ Congresso Mundial de Filosofia, na Bulgária, Richard Routley certificava, em 1973, a abertura de uma nova era na ética filosófica (Routley, 1973). O autor defendia que a necessidade de uma ética aplicada ao ambiente exigia um quadro conceptual distinto dos princípios fundamentais sobre os quais se haviam apoiado as éticas clássicas ocidentais, em que o ser humano era entendido como o locus exclusivo de valor intrínseco (Scherer, 1982).

Tradicionalmente o raciocínio ético aplicava-se apenas à esfera dos comportamentos humanos, uma vez que apenas os seres humanos se encontravam em condições de fazem parte da comunidade moral (pela posse da racionalidade), isto é, do conjunto de seres em benefício dos quais pesam restrições normativas na conduta dos agentes morais (Hottois, 2003) ${ }^{3}$. Tratava-se de um modelo intersubjetivo do raciocínio ético que não permitia que se conferisse estatuto moral a seres não humanos (animais, plantas, espécies, ecossistemas). Como não eram entendidos enquanto fins em si mesmos (Kant, 2010), considerava-se que esta lacuna deixava qualquer organismo não humano vulnerável face ao imenso poder com que a ação 
humana se revestia.

$\mathrm{O}$ artigo de Routley marcou um momento fundamental no conceito de antropocentrismo que haveria de dominar até hoje, enquanto visão em que a natureza não humana é considerada de acordo com a satisfação das necessidades humanas e/ou contribui para a promoção de valores e interesses exclusivamente humanos. Plantas, animais, comunidades bióticas e ecossistemas teriam aí um valor meramente instrumental.

Todavia, ao pensarmos nesta caracterização do antropocentrismo pelo designado não antropocentrismo, consideramos estar em presença de um conceito guarda-chuva que acolhe sob uma mesma denominação perspectivas bastante diferenciadas e, nalguns casos, irredutíveis.

A consolidação desta leitura do antropocentrismo (Hottois, 2003) fez-se pela construção de uma genealogia que identifica como antropocêntricas algumas das mais díspares tendências do pensamento ocidental. Referimo-nos à definição aristotélica do homem enquanto animal racional, por sua diferença específica; à interpretação judaico-cristã do ser humano enquanto criatura privilegiada e administrador, com plenos poderes, da restante natureza; e à expressão cartesiana do homem enquanto senhor e possuidor da natureza (Descartes, 2014), na linha de um dualismo ontológico (White, 1967).

Num afã culpabilizador e, sobretudo, reparador dos estragos ambientais produzidos pela civilização ocidental, alguns irreversíveis e de gravidade extrema, é certo, esta caracterização do antropocentrismo não nos parece adequada ou satisfatória. A começar porque não atende às significações e aos contextos específicos dos autores e épocas que à partida condena. Senão, vejamos.

Certamente que a definição grega do ser humano enquanto animal racional, seja numa dimensão puramente epistemológica, seja na projeção ética da excelência enquanto vida de virtude, se encontra longe de advogar a superioridade dos usos humanos da natureza. Basta que se recupere a própria concepção grega de physis, que veio originar o latim natura. A physis era entendida por Aristóteles como a substância ou essência dos seres que têm em si mesmos o princípio do seu próprio movimento (Metafísica, livro $\Delta, 1014$ b 15-1015 a 20; Física, livro II, 192b-193b).

É, então, a fonte ou princípio interno organizador que estrutura originalmente o desenvolvimento dos seres e um processo de devir ordenador da geração e do crescimento dos seres naturais: humanos e não humanos. Para além disso, a geração natural é marcada por um modo ordenado e harmónico de proceder - o conceito de physis está em íntima correlação 
com o de kosmos enquanto representação de um Universo ordenado - o que permitiu introduzir, essencialmente com os estóicos, a ideia da natureza como modelo privilegiado de ação moral. A aproximação entre o ser humano e a natureza parece-nos, pois, óbvia.

Quanto à consideração da antropologia judaico-cristã como segunda raiz do antropocentrismo, apresenta como base o primeiro livro da Bíblia, segundo o qual o ser humano foi criado à imagem e semelhança de Deus. Este privilégio conferiu-lhe desde a origem um estatuto ontológico e ético especial na hierarquia das criaturas, com um valor inerente superior ao de qualquer outro ser da natureza. Todavia, parece-nos fundamental sublinhar que o preceito divino Enchei e dominai a terra (Genesis, I, 1, 28-31) não se identifica com um controlo e uma relação meramente utilitarista. É de uma perspectiva do "cuidar" que se trata, parecendo-nos fundamental nesse contexto ter sido o ser humano a nomear todos os animais criados por Deus, numa atitude de cooperação com a própria ação criadora divina. Para além disso, o capítulo termina com a contemplação divina da criação: Deus viu tudo o que havia feito e tudo era muito bom. Tendo sido tudo obra de Deus, que sentido faria introduzir uma clivagem na obra divina mediante a dominação possessiva e exploradora de toda a criação por uma única criatura? Aliás, no século XII, a leitura franciscana de uma relação fraterna do ser humano com todos os seres vivos - ecologista avant la lettre - veio afirmar precisamente a visão cristã da natureza enquanto parceira no caminho do Homem para Deus.

Já no que respeita ao pensamento de Descartes, também não nos parece legítima a sua identificação com uma tirania utilitária humana sobre a natureza, tal como a veem os antiantropocentristas dos séculos XX e XXI. Por um lado, porque tal como acontecia na Grécia antiga ou nos alvores do judaico-cristianismo, a modernidade encontrava-se historicamente longe da crise ambiental contemporânea e, de acordo com o estado de desenvolvimento técnico e tecnológico dos instrumentos de exploração dos recursos naturais, a natureza era ainda entendida, e com alguma legitimidade empírica, enquanto reservatório infindável e omnipotente de recursos. Por outro lado, o sentido íntimo do pensamento cartesiano deve ser inserido no contexto epistemológico e metafísico de exaltação pela descoberta das potencialidades dos saberes científicos emergentes na modernidade, como era a física de inspiração matemática.

Se recuperarmos o contexto da sexta parte do Discurso do Método, onde Descartes se refere ao ser humano como senhor e possuidor da natureza, nela encontramos a defesa de uma visão prática da filosofia, por oposição à visão escolar especulativa, tese que se enquadra 
no paradigma moderno do conhecimento enquanto produção e não mera contemplação. Assim, o que Descartes está a defender é que um conhecimento aprofundado da natureza nos permite agir com maior segurança, rentabilizando os saberes adquiridos e, sobretudo, descobrindo potencialidades inauditas na nossa relação com o que nos rodeia. Esta leitura integradora parece-nos ficar esquecida na condenação da modernidade cartesiana enquanto antropocêntrica.

Por estes argumentos, parece-nos que o conceito de antropocentrismo apresentado deve ser revisto, quanto às origens que lhe são atribuídas, bem como ao enquadramento que se lhe atribui para a relação entre o ser humano e a natureza. O problema surge quando se identifica o antropocentrismo com a causa de todos os estragos ambientais e, alargando a semântica permitida pelo conceito, nele se incluem sentidos como arrogância, domínio, imperialismo e, até, chauvinismo humano (Routley, 1980), tomando a parte pelo todo.

Neste contexto, consideramos útil a distinção entre antropocentrismo forte e antropocentrismo fraco, apresentada e desenvolvida por autores como Bryan Norton e Eugene C. Hargrove ${ }^{4}$.

O pragmatista Bryan Norton retoma a questão de Richard Routley e, partindo também de uma resposta positiva, apresenta contudo uma proposta totalmente distinta: sim, é necessário uma nova ética qualitativamente diferenciada das leituras clássicas da tradição ocidental para fazer face aos desafios ambientais lançados pela ação humana. Todavia, este novo paradigma deve assumir-se como uma ética de matriz não individualista. Norton defende que a dicotomia clássica entre antropocentrismo e não-antropocentrismo deve substituir-se por outra de maior relevância ética: individualismo versus não-individualismo (Norton, 1984).

Quer as teorias éticas de matriz teleológica, quer as teorias de matriz deontológica, centraram-se na avaliação das ações mediante promovam o bem ou o mal do ponto de vista dos indivíduos afetados por elas: a unidade básica de justificabilidade ética é, assim, individual. Norton defende que este não é um pressuposto que possa legitimamente fundar uma leitura ética ambiental, já que a base a adotar deverá ser uma proteção de longo alcance do futuro, mesmo que isso colida com o que se considere bom do ponto de vista dos indivíduos ${ }^{5}$. No seu entender, este deveria ser o salto qualitativo reclamado pela ética ambiental enquanto nova ética, já que insistir na via não-antropocêntrica como o único enfoque para uma ética ambiental exige compromissos ontológicos com a descoberta de um valor intrínseco na natureza que se tornam teoricamente difíceis de gerir e que, na prática, não 
acrescentam eficácia na resolução dos problemas ambientais.

Conforme teremos ocasião de desenvolver no nosso próximo tópico, em termos epistemológicos o antropocentrismo não é uma questão de escolha, constituindo antes a forma que adquire a nossa experiência do mundo. Nas palavras de Eugene C. Hargrove: "Não penso que seja possível aos seres humanos evitarem ser antropocêntricos, dado que o que quer que seja que avaliemos será sempre de um ponto de vista humano (ou antropocêntrico)" (Hargrove, 1992, tradução nossa). Para além disso, "antropocentrismo" não é sinónimo de "instrumental", antes significa a consideração da realidade a partir da perspectiva humana (Hargrove; Costa Carvalho; pp. 150-151).

Assim, o que o antropocentrismo forte descura é a distinção entre a legítima percepção e valorização da natureza a partir do ponto de vista humano e uma atitude de desvalorização e instrumentalização abusiva da natureza, ou seja, identifica o registo epistemológico com o registo ético. Ora, apenas temos opção no plano ético, isto é, no modo como agimos dentro da nossa posição na natureza, já que em termos epistemológicos não nos é dado escolher pensar ou não pensar a natureza como seres humanos ${ }^{6}$.

Significa, então, que reconhecer o ser humano como o sujeito de moralidade, isto é, o único ser capaz de escolher uma ação baseada em princípios e valores que protejam outras entidades, não implica conceder-lhe o estatuto de objeto exclusivo dessa moralidade, ou seja, único portador de valor moral (Vogel, 1996, p. 165).

\section{O valor como propriedade das coisas}

O segundo equívoco que denunciamos prende-se com outro par de conceitos, também eles com grande impacto no debate da ética ambiental: valor instrumental versus valor intrínseco.

O designado não antropocentrismo entende que o valor intrínseco é simplesmente descoberto pelo ser humano na natureza, sendo anterior e independente da percepção e da conceptualização da experiência. Por contraponto, instrumental é o valor que o ser humano atribui aos seres naturais, entendendo-os não como fins em si mesmos, antes como meios para concretizar os seus próprios fins.

Esta perspetiva, que tem sido defendida por autores como Holmes Rolston III (1989; 1994), visa alargar o âmbito da considerabilidade moral, estendendo-a a entidades como plantas, animais e ecossistemas, seres a quem tradicionalmente não se reconhecia valor 
próprio. Assim, afirma-se que uma vez que estes seres são física e ecologicamente distintos do ser humano, existindo antes, para além e depois de nós, devemos conceder-lhes autonomia axiológica, isto é, um valor intrínseco objetivo.

Reflitamos um pouco nas implicações ontológicas, éticas e epistemológicas desta posição.

Em termos ontológicos, a leitura não antropocêntrica do valor intrínseco compromete-se com um realismo que postula que o valor é uma propriedade objetiva das coisas, a par com outras características como a extensão, o peso, ou a cor, consistindo no seu caráter próprio enquanto merecem mais ou menos estima por parte dos sujeitos, mas independentemente desses sujeitos (Lalande, 2006, p. 1183). Em termos éticos, alargam-se as restrições que pesam sobre os agentes morais humanos face a seres a quem se atribui valor intrínseco. A conduta humana é restringida em termos normativos, e não apenas prudenciais, isto é, tratar estes seres como fonte de interesse próprio não depende do arbítrio do agente moral, decorrendo do seu caráter, mas de um imperativo ético que lhe é exterior. Mas é em termos epistemológicos que a teoria não antropocêntrica do valor intrínseco nos parece levantar os maiores problemas, uma vez que o critério de validação deste realismo ontológico terá necessariamente que decorrer de uma convenção... humana.

A sutileza para a qual chamamos a atenção está, aqui, não no valor que se concede a uma determinada entidade, mas no modo como se apresenta a origem dessa valoração: se a colocamos na entidade mesma, dizendo que ao sujeito compete o mero papel de reconhecer o valor que aquela, por si mesma, já possui, falamos de valor intrínseco; já se a fazemos depender de uma atribuição do sujeito, o valor será instrumental. Contudo, repare-se, quem atribui ou reconhece esse valor é sempre o ser humano, a partir de um ponto de vista humano. É que mesmo o mais famoso dito de A. Leopold, think like a mountain (1968), é ainda uma projeção epistemológica. Pensar como uma montanha é um convite para que nos situemos na escala temporal dos processos geológicos, descentrando-nos do nosso tempo medido em anos, meses, dias, horas, minutos, segundos, nano-segundos. Todavia, é ainda pensar... e pensar, este pensar a que se refere Leopold, é exclusivo dos seres humanos ${ }^{7}$.

A este propósito, julgamos paradigmática uma passagem do Assim falava Zaratustra, de Nietzsche:

Antes de tudo, o homem atribuiu valores às coisas, a fim de se manter - começou por criar um sentido para as coisas, um sentido humano! Por isso, ele se chama "homem", isto é, aquele que avalia. Avaliar é criar. Escutai isto, ó criadores! O próprio ato de avaliar é que constitui o tesouro e a joia de todas as coisas avaliadas. Só mediante o avaliar é que há valor, e, sem a avaliação, a noz da existência seria 
oca. (Nietzsche, 1996: 67-68) ${ }^{8}$

Reconhecendo a centralidade dos processos valorativos, o filósofo alemão justifica que o sentido e o valor que as coisas têm foi de nós que o receberam: o ser humano não o conquistou, não o encontrou, não o recebeu, antes criou-o.

De regresso ao debate ambiental numa perspetiva ética, não consideramos necessário prescindir em absoluto do valor intrínseco, pois que é certamente unânime a consideração de que há coisas que valem por si mesmas (seja em termos éticos, estéticos, políticos, espirituais ou religiosos). Neste contexto, possuir valor intrínseco significa que esse valor não decorre dos interesses do avaliador, mas da entidade que é avaliada e define-se em termos do que constitui o seu bem ou que, em si, é digno de estima. Mesmo que esse valor só possa ser conferido pelo juízo de uma consciência discursiva humana.

Insistir na consideração de que o valor é uma propriedade que as coisas possuem, independentemente de uma consciência que o identifique e verbalize, perpetuará posturas incomunicáveis no seio de uma área que, como a ética ambiental, muito tem a fazer pela atual crise ecológica, sob prejuízo da promoção de ações eficazes.

O pragmatismo ambiental tem investido nesta abordagem, rejeitando absolutos morais e insistindo na dimensão contextual e pluralista de qualquer atribuição valorativa não instrumental $^{9}$. Adiante recuperaremos este tópico. Por agora, detenhamo-nos na importância desempenhada no debate pela concepção de natureza adotada e nos equívocos que também aí são vinculados.

\section{Um conceito desumanizado de natureza}

O terceiro equívoco que encontramos fortemente disseminado na visão dicotómica que opõe antropocentrismo e não antropocentrismo radica no próprio conceito de natureza.

A perspetivação da ética ambiental como resposta ao antropocentrismo forte promoveu uma distanciação entre a natureza e o ser humano. Apesar de advogar a necessidade de uma reconsideração do ser humano a partir de um ponto de vista natural, o modo como os discursos ditos não antropocêntricos foram produzidos e reproduzidos sedimentou a assunção de que essa relação não deveria ser bidirecional. Passamos a explicar.

Os discursos de fundo ecocêntrico, biocêntrico e até zoocêntrico confluem no descentramento da perspectiva humana e na defesa de modos de entender a realidade baseados em características como a capacidade autoreguladora dos ecossistemas, a posse da 
vida, a capacidade de sofrer ou ainda de ser sujeito de uma vida ${ }^{10}$. Apesar de estas características se encontrarem nos seres humanos, o fundamental aqui é que também se encontram em entidades não humanas e, assim, não existe qualquer razão para atribuir privilégios à vida humana (seria especismo, de acordo com o famoso conceito divulgado por Peter Singer, 1975).

Esta viragem não antropocêntrica implicou então longos investimentos na naturalização da representação do ser humano. Para tanto, foi certamente decisivo o apoio concedido pela biologia pós-darwiniana, sobretudo nas suas vertentes ecológicas.

Contudo, apesar de os não antropocentristas terem promovido a naturalização do ser humano, lutaram contra o movimento inverso de humanizar a natureza (Smulewicz-Zucker, 2012). A conotação do antropocentrismo com a arrogância e o imperialismo humanos levou a que se procurassem apenas traços da natureza no homem, mas se entendessem todas as marcas humanas no ambiente como antinaturais e indesejáveis.

Esta desumanização (anti-natural) da natureza condiciona obviamente a percepção que temos do nosso lugar no mundo e, em certa medida, compromete a dimensão prática dos discursos éticos no que respeita ao ambiente: se os não antropocentrismos defendem posturas teóricas que nos dizem que somos natureza, como nos poderemos integrar nessa mesma natureza se, depois, desconsideramos o que nos distingue enquanto espécie?

Que as culturas humanas afetam a estrutura e o funcionamento dos ecossistemas não significa apenas que os perturbam quando se dedicam a formas de exploração intensiva e desregulada dos recursos naturais. Implica, antes, que se pretendermos formular um conceito completo de natureza, no seu contexto global e integral, teremos que aí integrar a nossa dimensão cultural enquanto expressão do ser natural que somos. Os sistemas naturais, ainda que se autorregulem e pautem por transformações ecológicas e evolutivas numa escala de milhões de anos, cruzam-se inevitavelmente com os sistemas culturais bastante mais recentes, porém decisivos e realmente transformadores. Não estamos, obviamente, perante esferas separadas, já que o bem-estar do ser humano está intimamente dependente do bem-estar da natureza e vice-versa.

Contudo, quando as teorias não antropocêntricas tecem as suas críticas à pegada humana destruidora do ambiente, referem-se maioritariamente às sociedades ocidentais ditas civilizadas e, tomando a parte pelo todo, negligenciam formas de vida periféricas que, ainda que quantitativamente representem uma minoria, em termos qualitativos devem obrigatoriamente ser consideradas. Neste sentido, a abordagem biocultural tem insistido na 
recuperação das relações entre a natureza e os modos de expressão próprios do ser humano, partindo da etnobiologia para compreender a adaptação que várias culturas (minoritárias) fazem, de modo dinâmico, do ambiente em que se encontram.

Luisa Maffi, uma das impulsionadoras do movimento de defesa da diversidade biocultural chama a atenção especificamente para os povos indígenas de várias zonas do planeta $^{11}$ e para o modo como, a par com a rápida depleção da biodiversidade mundial, assistimos à extinção do património cultural da humanidade (fenómeno também designado como “extinção de experiência", L. Maffi, 2001, p. 7).

A autora apresenta, assim, a noção de diversidade biocultural para se referir à multiplicidade e à profunda interrelação das manifestações da vida na Terra, entendendo a vida nas suas dimensões biológica e cultural, no quadro de um sistema sócio-ecológico complexo em constante co-adaptação. A perspectiva biocultural assenta num tripé conceptual que entrosa língua, conhecimento e ambiente e defende uma inter-relação constitutiva e irrecusável entre o ser humano e a natureza, concretizada no binómio natureza-cultura.

Significa que o mundo natural não se pode separar do mundo humano (deveríamos, antes, falar de duas dimensões diferentes de um único mundo), já que são constituintes de um mesmo todo complexo, o que implica aceitar não apenas uma (longa) história comum, mas também uma evolução conjunta ${ }^{12}$. A tónica é colocada na perspectivação das diferentes culturas enquanto padrões orientadores da ação concreta e contextual dos indivíduos e das comunidades sobre o ambiente, defendendo a recuperação de modos de viver e de dizer antigos e endémicos, que tendem a perder-se nos atuais processos de globalização (Maffi; Woodley, 2010).

Assim, a salvação da biodiversidade será uma utopia a menos que se coordene com a preservação do património cultural da humanidade, já que a diversidade e a pluralidade são fatores de enriquecimento e de fortalecimento contra potenciais predadores biológicos e colonizadores culturais. Segundo Luisa Maffi, é necessário reconhecer que a perda de biodiversidade natural não constitui o núcleo da crise ambiental contemporânea, mas antes a perda da diversidade biocultural ${ }^{13}$.

Silenciar esta copertença e pretender desumanizar a natureza constitui a causa de vários problemas filosóficos. Ontologicamente, conduz a uma caracterização incompleta quer da natureza, quer do ser humano que, como vimos, se constituem em inter-relação ${ }^{14}$; eticamente, proporciona uma cisão entre o modo de entender o curso dos eventos naturais e o sentido do dever condutor da ação humana. 
Recuperamos aqui uma distinção do filósofo francês Paul Ricoeur entre acontecimento e ação (1988, p. 30). Ricoeur coloca na intencionalidade o critério que distingue o acontecer do fazer. Um acontecimento ocorre sem que a vontade do sujeito seja interveniente, já a ação permite ser nomeada e explicada de acordo com o motivo que esteve na sua origem e que a torna inteligível. É a intencionalidade que coloca em cena o agente moral, sendo condição de possibilidade de todo o processo ético porque confere significação à sua conduta.

Desta forma, torna-se essencial promover a integração do ser humano na natureza, sublinhando a sua especificidade enquanto único agente moral, dotado de consciência ética e capaz de uma ação intencionalmente responsável. Humanizar a natureza é partir desta integração ontológica e, sobretudo, ética.

Sem nos querermos alongar, remetemos aqui para a conceção contemporânea de responsabilidade, tal como é apresentada por Hans Jonas, princípio ontológico-ético diretamente proporcional à vulnerabilidade que a ação técnica encontra (Jonas, 1998). Poderíamos, assim, recuperar a tradição ambiental da stewardship (Berry, 2006), conceito de inspiração judaico-cristã cujo sentido se aproxima de "custódia", enquanto gestão cuidadora ou zelo pela Terra, que a valoriza enquanto património a entregar às gerações futuras. Numa afirmação de Hans Jonas que subscrevemos, o ser humano seria, então, entendido como o único possível cuidador ou depositário desse fundo (Jonas, 2001, p. 283) ${ }^{15}$.

\section{A ética ambiental como filosofia aplicada}

Após as considerações apresentadas acerca das noções de antropocentrismo, valor e natureza, neste último tópico da nossa reflexão referimo-nos à própria noção de Ética Ambiental e ao papel que a mesma (não) tem assumido no debate sobre a grave crise ambiental em que nos encontramos.

Como vimos, entendemos que o quadro epistemológico de referenciação da experiência humana é naturalmente antropocêntrico, uma vez que o mecanismo de valoração das entidades (humanas e não humanas) acontece no seio de uma consciência discursiva. Neste contexto, e tendo ainda por base uma concepção que entende o ser humano como natural e a natureza como humana, importa estabelecer a postura da Ética Ambiental.

A ideia de que a Ética Ambiental surge como uma filosofia teórica aplicada surge essencialmente dos monismos morais anti-antropocêntricos, a que já nos referimos. Como temos visto, estas teorias assumem um compromisso conceptual com um amplo quadro de 
referência ontológico, epistemológico e ético, ocupando-se do desenvolvimento e aprofundamento da coerência teórica entre essas várias dimensões. Tem, assim, assumido uma função de fillosofia (teórica) aplicada, num modelo top-down de apoio às decisões teóricas. E este é um equívoco que nos parece condicionar a comunicação entre os reais problemas ambientais com que a humanidade se depara (que nunca são problemas em abstrato, mas situações concretas em comunidades específicas), e as teorias éticas como apoio instrumental de suporte na justificação e fundamentação de possíveis cursos de ação.

A proposta do pragmatismo ambiental também aqui nos parece de extremo interesse, já que aposta numa abordagem contextual dos problemas em análise, de acordo com um processo constante de reflexão e de deliberação moral, a partir das várias dimensões presentes numa mesma questão real e concreta. Desta feita, a Ética Ambiental pode assumir-se, não como filosofia teórica aplicada, mas como filosofia prática orientada pela formulação de quadros de referência a partir de problemas concretos. Pelo contrário, uma reflexão teórica isolada de um debate plural e contextual com os diversos atores e perspectivas implicados continuará a confinar a Ética Ambiental aos claustros de uma simples discussão acadêmica.

A gravidade dos atuais problemas ambientais reclama abordagens interdisciplinares que cruzem saberes e metodologias, na procura de perspectivas integradoras que não ponham em causa a integridade natural e humana (Costa Carvalho, 2014). Nesse contexto, a Ética Ambiental pode estabelecer-se como núcleo aglutinador de um debate esclarecido já que, pela sua dimensão normativa, permite situar as representações e as práticas num horizonte regulador de consideração fundamental do ser humano e da natureza.

Em 1982, Stephen Toulmin, referindo-se à projeção que a ética biomédica assumira após a década de 70, afirmava que a Medicina tinha salvo a vida da Ética. Com os dilemas provenientes da tecnicização das prática médicas, os eticistas foram confrontados com a necessidade de intervir através do debate de determinados temas e alinhando socialmente ao lado de políticos e economistas.

É uma viragem análoga que a Ética Ambiental reclama, abandonando uma discussão geral de princípios e regras, e repensando-se a partir do equilíbrio entre a sua vertente teórica e os problemas reais.

Sem fazermos a apologia de uma casuística estrita, consideramos que se a natureza sem a ética é cega, a ética sem a natureza será insuficiente. Os pressupostos e as implicações subjacentes às decisões e atuações com impacto ambiental devem ser propriamente situados em termos normativos, garantindo que se adequam a um projeto humano comprometido com 
princípios e valores fundadores. Por outro lado, os princípios e valores que fundam a atividade dos sujeitos morais, sem deixarem de se constituir a um nível meta-ético, ganham consistência ao serem configurados como eixos de interpretação da realidade circundante.

Não tendo sido nosso objetivo a apresentação de questões ambientais concretas, mas explorar alguns fundamentos e pontos de referência da discussão ambiental, terminamos com a sistematização de quatro eixos que consideramos deverem nortear a Ética Ambiental nesta segunda década do século XXI:

1. o modelo de uma ética antropocentrada que assuma que os critérios de considerabilidade moral são inteira e exclusivamente estabelecidos pela avaliação humana e que possa, assim, coerentemente defender o compromisso e a responsabilidade do ser humano, não apenas perante a sua ação individual, mas sobretudo face à vulnerabilidade exterior de toda a biosfera, conferindo-lhe valor intrínseco;

2. a consideração da qualidade diferenciadora do ser humano enquanto ser moral e, consequentemente, a perspectivação do valor enquanto produto da interpretação e da avaliação que apenas um ser conscientemente discursivo pode fazer da natureza;

3. uma conceção da natureza que inclua o ser humano, naquilo que ele tem de próximo e naquilo que o especifica em relação às demais entidades naturais;

4. a reflexão ética enquanto campo privilegiado para problematizar questões ambientais do mundo contemporâneo, permitindo o encontro entre vários contextos e pontos de vista e oferecendo suportes teóricos plurais, dialogados e adequados para a resolução dos mesmos.

Desta forma, afastamo-nos de um registo estritamente acadêmico de reivindicações teóricas por vezes difíceis de justificar sobre a natureza dos valores, sem abdicarmos de estruturas conceptuais coerentes e racionais que permitam ser um suporte crítico das decisões que prejudicam a natureza e afirmando que há limites claros e urgentes para a ação humana sobre o ambiente. 


\section{Notas:}

1 Uma versão preliminar deste estudo foi apresentada oralmente no IV Meeting on Ethics and Political Philosophy, organizado pelo Centro de Estudos Humanísticos da Universidade do Minho, em 2013. A autora agradece a oportunidade de repensar algumas das questões abordadas, quer nesse encontro, quer pelos revisores da Revista Ethic@, cujas sugestões muito contribuíram para melhorar a forma final do texto.

2 Magda Costa Carvalho é Professora Auxiliar no Departamento de História, Filosofia e Ciências Sociais da Universidade dos Açores e membro do Centro de Filosofia da Universidade de Lisboa. É doutorada em Filosofia, com uma tese sobre o conceito de "natureza" em Henri Bergson. Presentemente, as suas principais áreas de investigação são a Ética Ambiental e a Filosofia para Crianças. Email: magda.ep.teixeira@uac.pt

3 A definição de "comunidade moral" é passível de várias outras leituras que, contudo, extrapolam a economia do presente artigo (ainda que nele estejam implicadas).

${ }^{4}$ Crítica do atomismo lógico e ontológico, Barbara Muraca apresenta uma proposta para o discurso ambiental assente em valores relacionais como alternativa aos dualismos metafísicos subjacentes às tradicionais leituras que opõem antropocentrismo e não antropocentrismo. A noção de uma "relacionalidade fundamental" que a autora constrói a partir da filosofia do processo de Alfred North Whitehead assenta em entidades, processos e coletivos sistémicos. É nesta base que a autora se refere a um "antropocentrismo profundo" (deep anthropocentrism) (Muraca, 2011).

${ }^{5} \mathrm{O}$ pensamento de Norton promove uma interessante aproximação entre ecocentrismo e antropocentrismo fraco, Norton, 1987.

${ }^{6}$ Esta postura foi já apelidada como "antropocentrismo perspetivo" (Attfield, 2011).

${ }^{7}$ B. Norton tem desenvolvido com grande conhecimento, profundidade e coerência uma interpretação da obra de Aldo Leopold que o afasta da leitura não antropocêntrica, Norton, 1991: 57-58.

${ }^{8}$ Nietzsche estabelece um parentesco etimológico entre a palavra Mensche, "ser humano" em alemão, e o latim mensor, "aquele que mede".

9 Sem advogarmos em exclusividade o pragmatismo ambiental, aceitamos como válidos dois dos seus fundamentos: o pressuposto substantivo e o pressuposto metodológico. Pelo primeiro, seguimos os conteúdos epistemológicos e éticos do pragmatismo (dimensão comunitária e intersubjetiva da verdade, pluralismo de valores), pelo segundo, a sua metodologia (procurar a diferença prática de uma determinada querela para justificar a sua legitimidade), Katz, 1999.

${ }^{10}$ Pensamos em autores como Arne Naess, Paul Taylor, Peter Singer ou Tom Regan.

${ }^{11}$ Em 1996, esta antropóloga canadiana fundou com outros especialistas uma organização internacional não governamental e sem fins lucrativos designada Terralingua e assente no conceito de "biocultural diversity" (diversidade biocultural), cf. www.terralingua.org (acedido a 6 de agosto de 2015).

12 Este pressuposto é exemplificado através de alguns estudos ecológicos e etnológicos de larga escala que cruzam a distribuição de grandes vertebrados endémicos (como mamíferos, pássaros, répteis e anfíbios) e de línguas endémicas no mundo. Países como o Brasil, o Perú, o Equador, os Camarões, o Quénia, a Indonésia ou a Índia (apenas para citar alguns exemplos) apresentam índices elevadíssimos de ambos. É muito interessante que estes países se situam tendencialmente na região sul do globo e não na região norte, onde encontramos a tendência para um paradigma cultural homogéneo e hegemónico. Boaventura Sousa Santos aborda precisamente esta questão na sua obra Epistemologias do Sul, referindo-se à imposição colonizadora do modelo moderno de ciência (oriundo dos países do hemisfério norte) que tendeu para uma extinção paulatina do pluralismo epistemológico dos países do sul. O sociólogo refere-se precisamente ao problema da preservação da biodiversidade, ameaçada pela sobrevalorização da intervenção da ciência e da técnica face a formas de vida indígenas, Boaventura Sousa Santos; Maria Paula Meneses, 2009, p. 49. 
${ }^{13}$ É paradigmático que, das cerca de 6000 línguas faladas atualmente em todo o mundo, metade sejam faladas por comunidades com menos de 10000 habitantes e que, dessas, metade seja falada por comunidades de 1000 habitantes ou menos. Ou seja, a maior parte da diversidade linguística mundial reside em pequenas comunidades de povos minoritários ou indígenas. $\mathrm{O}$ triângulo de relações entre os conceitos de habitat-habit-inhabitant não pode cair se quisermos pensar eticamente os problemas ambientais, procurando eficácia nas respostas concretas que lhes damos. Integrar a perspetiva da diversidade biológica, linguística e cultural nas representações culturais, políticas públicas e práticas, permite melhorar a nossa capacidade de conservar a diversidade biocultural. O ser humano é uma componente dos ecossistemas e da biodiversidade, e para o comprovar basta atender às designadas cultural landscapes, Rozzi; Poole, 2011: 53-74.

14 "Landscapes are anthropogenic not only in the sense that they are physically modified by human intervention, but also because they are symbolically brought into the sphere of human communication by language: the human relationship onto the land is inscribe in human culture.", Maffi, 2010, p. 12.

${ }^{15}$ Crítico das leituras tradicionais do antropocentrismo, Steven Vogel advoga na sua última obra, Thinking like a Mall, que é hoje impossível escaparmos a uma natureza transformada pela ação humana. Por isso, considera o autor, o conceito de natureza deve ser substituído pelo de ambiente, incluindo obrigatoriamente o mundo construído (Vogel, 2015). 


\section{Referências bibliográficas:}

R. Attfield. Beyond Anthropocentrism. Royal Institute of Philosophy Supplement, 69 (2011): pp. 2946.

S. Berry, ed. Environmental Stewardship. Critical Perspectives, Past and Present. Edinburgh: Bloomsbury T\&T Clark, 2006.

M. Costa Carvalho. Da integridade enquanto conceito ético: uma perspectiva ambiental, Confluências Bioéticas, Lisboa: Universidade de Lisboa, 2014, pp. 205-222.

R. Descartes. Discurso do Método. Lisboa: Edições 70, 2014.

E. C. Hargrove. Weak anthropocentric intrinsic value, The Monist, 75 (1992): pp. 183-207.

E. C. Hargrove; M. Costa Carvalho. On Environmental Philosophy: an interview with Eugene C. Hargrove, Kairos. Revista de Filosofia \& Ciência, 11 (2014): pp. 139-161.

G. Hottois. Antropocentrismo. In Nova Enciclopédia da Bioética, ed. G. Hottois; J. M. Missa. Lisboa: Instituto Piaget, 2003.

I. Kant. Duties toward animals and spirits. In Keller, David R., ed. Environmental Ethics. The big questions. Oxford: Wiley-Blackwell, 2010.

E. Katz. A pragmatic reconsideration of anthropocentrism. Environmental Ethics, 21 (1999) 4: pp. 377-390.

H. Jonas. The phenomenon of life. Toward a philosophical biology. Illinois: Northwestern University Press, 2001.

H. Jonas. Le principe responsabilité. Une éthique pour la civilisation technologique. Paris: Flammarion, 1998.

A. Lalande. Vocabulaire technique et critique de la philosophie, Paris: Quadrige/Presses Universitaires de France, 1996.

A. Leopold. A Sand County Almanac and Sketches Here and There. Oxford: Oxford University Press, 1998.

L. Maffi, ed. On biocultural diversity. Linking language, knowledge, and the environment. Washington/London: Smithsonian Institution Press, 2001.

L. Maffi; E. Woodley. Biocultural diversity conservation. A global sourcebook. London: Earthscan, 2010 .

B. Muraca. The Map of Moral Significance: a New Axiological Matrix for Environmental Ethics, Environmental Values, 20 (2011): pp. 375-396.

F. Nietzsche. Assim falava Zaratustra. Um livro para todos e para ninguém. Lisboa: Círculo de Leitores, 1996.

B. G. Norton. Environmental Ethics and Weak Anthropocentrism. Environmental Ethics, 6 
(1984): pp. 131-48.

B. G. Norton (1991) Toward Unity Among Environmentalists. New York: Princeton University Press.

B. G. Norton. Why Preserve Natural Variety? Princeton: Princeton University Press, 1987.

P. Ricoeur. O discurso da Acção. Lisboa: Edições 70, 1988.

H. Rolston III. Philosophy Gone Wild. New York: Prometheus Books, 1989.

H. Rolston III. Value in Nature and the Nature of Value. Royal Institute of Philosophy Supplement, 36 (1994): pp. 13-30.

R. Routley. Is there a Need for a New, an Environmental Ethic?, Proceedings of the XVth World Congresso f Philosophy: 17th to 22nd September, Bulgaria: Sofia Press, 1973: pp. 205-210.

R. Routley; V. Routley. Human Chauvinism and Environmental Ethics. In Environmental Philosophy, eds. D.S. Mannison; M. McRobbie; R. Routley. Canberra: ANU Research School of Social Sciences, 1980: pp. 96-189.

R. Rozzi; A. Poole. Habitats-Habits-Inhabitants. A Biocultural Triad to Promote Sustainable Cultures. In O. Parodi et al., eds., Sustainable Develpment. Relationships to Culture, Knowledge and Ethics, Karlsruhe: KIT-Scientific Publishing, 2011: pp. 53-74.

B. Sousa Santos; Maria Paula Meneses. org. Epistemologias do Sul. Coimbra: Almedina, 2009.

D. Scherer. Anthropocentrism, Atomism, and Environmental Ethics, Environmental Ethics, 4, 1982: pp. 115-123.

P. Singer, Animal Liberation: a New Ethics for Our Treatment of Animals. New York: Random House, 1975.

G. R. Smulewicz-Zucker, ed., Strangers to nature. Animal lives and human ethics. Lanham: Maryland Lexington Books, 2012.

S. Toulmin. How Medicine Saved the Life of Ethics. In Perspectives on Biology and Medicine, 25, 1982: 736-750.

S. Vogel. Against Nature: The Concept of Nature in Critical Theory. New York: State University of New York Press, 1996.

S. Vogel. Thinking like a Mall. Environmental Philosophy after the End of Nature. New York: MIT Press, 2015.

L. White. The historical roots of our ecological crisis. Science, 155 (1967): pp. 1203-1207. 